\title{
Comportamento do Girassol Quando Cultivado em Área Tratada com o HERBICIDA 2,4-D ${ }^{1}$
}

\author{
Sunflower Behavior When Cultivated in 2,4-D Treated Areas
}

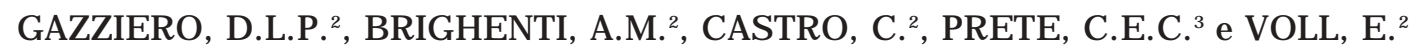

RESUMO - Com o objetivo de determinar o período adequado de semeadura da cultura do girassol (Helianthus annuus), em relação à aplicação de 2,4-D, foi realizado um experimento em condições de campo da área experimental da Embrapa Soja, Londrina-PR, durante o ano agrícola 1995/96. Os tratamentos estabelecidos foram doses do herbicida 2,4-D (0,0, 536 e $1.005 \mathrm{~g}$ e.a. $\mathrm{ha}^{-1}$ ) e épocas de semeadura da cultura. Dessa forma, a semeadura foi realizada um dia antes da aplicação do produto (-1 dia), no dia da aplicação (0 dia) e a 1, 4, 7, 10 e 13 dias depois da aplicação do herbicida. Os resultados indicaram que o girassol sofreu injúrias mais severas nas três primeiras épocas de semeadura (-1, 0 e 1$)$. Aumentando o tempo entre a aplicação das doses do herbicida e a semeadura do girassol, observaram-se menores danos causados à cultura. O experimento permitiu concluir que áreas tratadas com o 2,4-D nas doses de 536 e 1.005 g e.a. ha ${ }^{-1}$ podem ser cultivadas com girassol, desde que se mantenha um intervalo mínimo de quatro dias entre a aplicação do herbicida e a sua semeadura.

Palavras-chave: persistência no solo, herbicidas residuais.

\begin{abstract}
A field assay was carried out at the "Embrapa Soja", an experimental station in Londrina, Paraná, Brazil, to evaluate the adequate timing for sunflower sowing combined with 2.4-D, during the growing season of 1995/96. The treatments consisted of three rates of 2.4-D herbicide $\left(0.0,536\right.$ and 1,005 $\mathrm{g}$ a.e. $\left.\mathrm{ha}^{-1}\right)$ and seven periods of sunflower sowing: - 1 day (sunflower sowing was conducted one day before herbicide application); $O$ day (sunflower sowing and herbicide application were conducted at the same day) and sunflower sowing at one, four, seven, 10 and 13 days after herbicide application. The results showed that sunflower growth was reduced mainly when sowing occurred at a time close to the 2.4-D application. Reduced herbicide damage on sunflower plants was observed when a longer period was kept between sowing time and herbicide application. It was concluded that areas treated with 2.4-D at rates 536 and 1,005 $\mathrm{g}$ a.e. $\mathrm{ha}^{-1}$ can be used for sunflower cultivation provided at least a four day - period is kept between herbicide application and sunflower sowing.
\end{abstract}

Key words: soil persistence, residual herbicides.

\section{INTRODUÇÃO}

O conhecimento dos fatores que influenciam a atividade e a estabilidade de herbicidas no solo é de grande importância, uma vez que é possível explicar o sucesso ou o fracasso desses produtos no controle das plantas daninhas, na tolerância da cultura e na persistência destes em diferentes condições de meio ambiente.

Os sintomas de intoxicação observados nas plantas cultivadas devido à persistência de herbicidas no solo podem desaparecer à medida que a planta cresce, não chegando a afetar o rendimento da cultura (Griffin \& Barker, 1990).

1 Recebido para publicação em 23/6/2000 e na forma revisada em 8/2/2001.

2 Eng.-Agrônomo Pesquisador - Embrapa Soja, Caixa Postal 231, 86001-970 Londrina-PR. ${ }^{3}$ Prof. Dr. do Dep. de Fitotecnia, Universidade Estadual de Londrina, Caixa Postal 6001, 86051-990 Londrina-PR. 
Entretanto, pode ocorrer o inverso, ou seja, no início os sintomas são pouco visíveis e, à medida que a planta se desenvolve, eles se tornam mais pronunciados, afetando a produção (Brewster \& Appleby, 1983). Para a maioria dos herbicidas, as frações orgânica e argila do solo influenciam a disponibilidade desses produtos para as plantas. Podem sofrer ainda lixiviação, degradação mediante processos físico-químicos e biológicos, adsorção pelos colóides do solo, volatilização, fotodecomposição, além da absorção pelas plantas daninhas ou cultivadas (Beckie \& McKercher, 1989; Gallandt et al., 1989).

Com relação ao 2,4-D, vários estudos foram realizados no sentido de verificar o seu período residual no ambiente (Altom \& Stritzke, 1973; Foster \& McKercher, 1973; Plumb et al., 1977). Quando o produto é aplicado no solo, a molécula é degradada por processos microbiológicos (Loos, 1975; Rodrigues \& Almeida, 1995). O tempo necessário para esse herbicida atingir metade da sua concentração original (meiavida) é menor que sete dias (Smith, 1978). Em regiões quentes e úmidas, doses normais se dissipam em duas a quatro semanas (Silva \& Silva, 1991).

Uma preocupação dos agricultores e técnicos que realizam a semeadura direta do girassol é a possibilidade de persistência do 2,4-D no solo, tendo em vista a não-existência de informações precisas quanto à carência mínima entre sua aplicação e a semeadura direta da cultura. Muitos produtores aplicam o produto e semeiam logo em seguida, ou esperam alguns dias para realizar essa operação. No entanto, apesar de o 2,4-D possuir dissipação relativamente rápida no solo, dependendo das condições ambientais, podem ocorrer sintomas de intoxicação em plantas de girassol. No caso da semeadura direta da soja, esse produto deve ser utilizado com um intervalo mínimo de dez dias entre a aplicação e a semeadura (EMBRAPA, 1999).

O objetivo deste trabalho foi avaliar o comportamento do girassol semeado em várias épocas em relação à aplicação do herbicida 2,4$\mathrm{D}$, a fim de determinar a época mais adequada para se realizar a semeadura da cultura.

\section{MATERIAL E MÉTODOS}

O experimento foi conduzido no campo durante o ano agrícola 95/96, em área pertencente à Embrapa Soja, Londrina-PR, situada a $23^{\circ} 23^{\prime}$ de latitude sul e $51^{\circ} 11^{\prime}$ de longitude oeste.

O clima da região, segundo a classificação de Köppen, pertence ao tipo Cfa, ou seja, clima subtropical úmido, com chuvas em todas as estações, podendo ocorrer seca no período de inverno. A temperatura média anual está em torno de $20,7^{\circ} \mathrm{C}$, e a precipitação média anual, em torno de 1.615 mm (Corrêa et al., 1982).

O solo da área onde foi conduzido o experimento foi classificado como Latossolo Roxo Eutrófico, cujas análises física e química encontram-se na Tabela 1.

O delineamento experimental utilizado foi o de blocos casualizados com tratamentos arranjados em parcelas subdivididas, com quatro repetições. Cada bloco foi constituído por três parcelas, às quais foram aplicadas as doses do herbicida 2,4-D amina $\left(670 \mathrm{~g} \mathrm{~L}^{-1}\right.$ de equivalente ácido). Cada parcela foi dividida em sete unidades experimentais (subparcelas), nas quais foram estabelecidas as épocas de semeadura do girassol. A área da parcela foi de $28 \mathrm{~m}^{2}(2 \times 14 \mathrm{~m})$ e a da subparcela de $4 \mathrm{~m}^{2}$ $(2 \times 2 \mathrm{~m})$ sendo a área total do experimento de $336 \mathrm{~m}^{2}$.

Tabela 1 - Resultados das análises física e química do solo, para a camada de 0-20 cm, da área experimental. Embrapa Soja, Londrina-PR, 1995/96

\begin{tabular}{|c|c|c|c|c|c|c|c|c|c|c|c|c|}
\hline Argila & Silte & Areia & MO & \multirow{2}{*}{$\begin{array}{c}\mathrm{P} \\
\mathrm{mg} \mathrm{dm}^{-3}\end{array}$} & \multirow{2}{*}{$\begin{array}{c}\mathrm{pH} \\
\mathrm{CaCl}_{2} \\
\end{array}$} & K & $\mathrm{Ca}$ & $\mathrm{Mg}$ & $\mathrm{H}+\mathrm{Al}$ & SB & CTC & \multirow{2}{*}{$\begin{array}{l}\mathrm{V} \\
\% \\
\end{array}$} \\
\hline \multicolumn{4}{|c|}{ 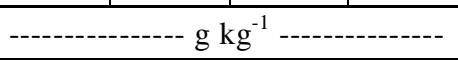 } & & & \multicolumn{6}{|c|}{ - } & \\
\hline 67 & 20 & 13 & 2,52 & 8,8 & 4,98 & 0,59 & 4,55 & 1,60 & 4,96 & 6,74 & 11,7 & 57,61 \\
\hline
\end{tabular}

${ }^{1}$ Resultados fornecidos pelo laboratório de análises de solos da Embrapa Soja. 
Foram utilizadas as doses de 0,0,536 e 1.005 g e.a. ha-1 do herbicida 2,4-D. A semeadura do girassol foi realizada um dia antes da aplicação do produto (-1 dia), no dia da aplicação (0 dia) e a 1, 4, 7, 10 e 13 dias após a aplicação do herbicida (DAA).

A pulverização foi feita no dia 28 de março, em pré-emergência da cultura. Utilizou-se pulverizador costal, a pressão constante (mantida por $\mathrm{CO}_{2}$ comprimido) de $270 \mathrm{kPa}$, equipado com barra de $1,5 \mathrm{~m}$ de largura e quatro bicos de jato plano 8002 , distanciados $0,5 \mathrm{~m}$, com volume de pulverização equivalente a $260 \mathrm{~L} \mathrm{ha}^{-1}$.

Por ocasião da aplicação do produto, a temperatura do ambiente era de $28{ }^{\circ} \mathrm{C}$. A umidade relativa do ar era de $60 \%$, estando o solo úmido na superfície e a velocidade do vento variando entre $1 \mathrm{e} 4 \mathrm{~km} \mathrm{~h}^{-1}$.

A semeadura foi feita utilizando o híbrido Cargill 11, com espaçamento entre linhas de $0,8 \mathrm{~m}$. Foram depositadas três sementes, distanciadas $0,35 \mathrm{~m}$, a uma profundidade de $4 \mathrm{~cm}$, através do uso de matraca, desbastandose para uma planta aos 10 dias após a semeadura. A adubação de semeadura foi realizada com $400 \mathrm{~kg} \mathrm{ha}^{-1}$ da fórmula NPK (5-25-25). Após 30 dias da semeadura, foi feita uma adubação em cobertura, com $40 \mathrm{~kg}$ de nitrogênio/ha.

Foram feitas duas contagens de estande de plantas de girassol, sendo uma aos 10 e outra aos 20 dias após a semeadura (DAS).

A toxicidade nas plantas de girassol foi avaliada visualmente aos 14, 28 e 42 DAS. O grau de fitoxicidade foi obtido através da escala percentual, em que $0 \%$ correspondeu à ausência de sintomas e 100\%, à morte de plantas.

Após 58 dias da semeadura da cultura, realizou-se a colheita da parte aérea das plantas de girassol em uma área de $1,5 \mathrm{~m}^{2}$, dentro de cada subparcela. Para determinação do peso da biomassa seca, toda a parte aérea das plantas de girassol foi cortada e acondicionada em sacos de papel devidamente identificados. Posteriormente, foi levada à estufa de circulação e renovação forçada de ar a $60-70{ }^{\circ} \mathrm{C}$ até obter massa constante, e o material foi pesado em balança graduada.

Os dados de estande de plantas, biomassa seca e fitotoxicidade foram submetidos à análise de variância pelo teste $\mathrm{F}$, e a comparação das médias, pelo teste de Tukey a 5\% de probabilidade. Em seguida, foi feita análise de regressão polinomial para os dados de biomassa seca e fitotoxicidade relativas às épocas de semeadura.

\section{RESULTADOS E DISCUSSÃO}

Na Tabela 2, estão apresentados os valores médios dos estandes de plantas de girassol aos 10 e 20 DAS. Observou-se que, para as duas doses do herbicida utilizadas, os estandes foram baixos em relação aos demais nas três primeiras épocas de semeadura. A dose de $1.005 \mathrm{~g} \mathrm{e.a.} \mathrm{ha-1}$ proporcionou redução no estande superior à dose de 536 g e.a. ha ${ }^{-1}$ nas três primeiras épocas de semeadura. Os valores médios de estande quando se semeou o girassol aos 4 DAA, na dose de 1.005 g e.a. ha ${ }^{-1}$, não diferiram significativamente dos valores obtidos quando se realizou a semeadura aos $7,10 \mathrm{e}$ 13 DAA. Os valores alcançados nas quatro últimas épocas de semeadura assemelham-se aos obtidos na testemunha.

A biomassa seca de plantas de girassol em função das diversas épocas de semeadura da cultura encontra-se na Figura 1. Houve incremento linear desta característica à medida que se aumentou o período de tempo entre a aplicação do produto e a semeadura da cultura. Nas três primeiras épocas de semeadura foram alcançados valores baixos de biomassa seca das plantas do girassol, quando comparados com os das demais épocas de semeadura e a testemunha (Tabela 2). Os valores médios da biomassa seca quando se semeou o girassol aos 4 DAA na dose de $1.005 \mathrm{~g}$ e.a. ha ${ }^{-1}$ não diferiram dos valores obtidos quando se realizou a semeadura aos 7, 10 e 13 DAA. Os valores médios alcançados nas quatro últimas épocas de semeadura assemelham-se aos obtidos na testemunha. Ao se instalarem culturas de dicotiledôneas, após ter sido aplicado o 2,4-D, é necessário esperar três dias entre a aplicação e a semeadura da cultura (Rodrigues \& Almeida, 1995).

A toxicidade nas plantas de girassol aos 14 DAS, em função das épocas de semeadura do girassol, encontra-se na Figura 2. Os sintomas de intoxicação diminuíram à medida que se afastou a época de semeadura da cultura 
do dia da aplicação do produto. Verifica-se que os valores mais altos da percentagem de fitotoxicidade foram atingidos nas três primeiras épocas de semeadura, não havendo diferença significativa entre os valores obtidos quando se semeou o girassol aos 4 DAA e aqueles atingidos quando se realizou a semeadura aos $7 \mathrm{e}$ 10 DAA (Tabela 2). Além disso, não foram observados quaisquer sintomas de intoxicação de plantas de girassol quando foi feita a semeadura aos 13 DAA nas duas doses estudadas. A presença do 2,4-D no solo estimula a atividade microbiana, incrementando sua taxa de decomposição (Souza et al., 1996). A dissipação também se torna mais rápida à medida que se realizam aplicações repetidas do produto, devido a aumento da população de microrganismos capazes de degradá-lo (Torstensson et al., 1975). Duah-Yentumi \& Kuwatsuka (1982), estudando a degradação do herbicida 2,4-D em solos corrigidos com adubação orgânica e mineral, verificaram que os microrganismos degradaram rapidamente o herbicida. Diversos fatores, como textura do solo, nutrientes e concentração do próprio herbicida, contribuem para sua rápida degradação.

Tabela 2 - Teste de Tukey para a interação das doses do herbicida 2,4-D x época de semeadura da cultura do girassol para as variáveis: estande de plantas de girassol aos 10 (E1) e aos 20 (E2) DAS, biomassa seca (BS) aos 58 DAS e toxicidade de plantas de girassol aos 14 (FIT1), aos 28 (FIT2) e aos 42 (FIT3) DAS. Embrapa Soja, Londrina-PR, 1995/96

\begin{tabular}{|c|c|c|c|c|c|c|c|c|c|c|c|c|c|c|c|}
\hline \multirow{2}{*}{ Épocas } & \multicolumn{3}{|c|}{ Dose 0 (zero) } & \multicolumn{6}{|c|}{ Dose 536 g e.a. ha ${ }^{-1}$} & \multicolumn{6}{|c|}{ Dose 1.005 g e.a. ha ${ }^{-1}$} \\
\hline & E1 & E2 & BS & E1 & E2 & BS & FIT 1 & FIT2 & FIT3 & E1 & E2 & BS & FIT 1 & FIT2 & FIT3 \\
\hline-1 & $36,75 \mathrm{a}$ & $35,50 \mathrm{a}$ & $442,50 \mathrm{ab}$ & $16,50 \mathrm{~b}$ & $17,50 \mathrm{c}$ & $284,00 \mathrm{~cd}$ & $67,50 \mathrm{a}$ & $65,00 \mathrm{a}$ & $61,25 \mathrm{a}$ & $6,25 \mathrm{bc}$ & $7,00 \mathrm{bc}$ & $146,00 \mathrm{~b}$ & $95,00 \mathrm{a}$ & $86,50 \mathrm{a}$ & $84,00 \mathrm{a}$ \\
\hline 0 & $38,25 \mathrm{a}$ & $35,75 \mathrm{a}$ & $367,25 \mathrm{~b}$ & $17,00 \mathrm{~b}$ & $18,00 \mathrm{c}$ & $192,50 \mathrm{~d}$ & $77,50 \mathrm{a}$ & $75,00 \mathrm{a}$ & $72,50 \mathrm{a}$ & $3,25 \mathrm{c}$ & $5,00 \mathrm{c}$ & $97,50 \mathrm{~b}$ & $97,50 \mathrm{a}$ & $98,00 \mathrm{a}$ & $96,75 \mathrm{a}$ \\
\hline 1 & $36,25 \mathrm{a}$ & $35,25 \mathrm{a}$ & $445,00 \mathrm{ab}$ & $22,75 \mathrm{~b}$ & $21,75 \mathrm{bc}$ & $221,25 \mathrm{~d}$ & $70,50 \mathrm{a}$ & $68,75 \mathrm{a}$ & $62,50 \mathrm{a}$ & $14,75 \mathrm{~b}$ & $15,25 \mathrm{~b}$ & $183,25 \mathrm{~b}$ & $91,50 \mathrm{a}$ & $91,50 \mathrm{a}$ & $82,00 \mathrm{a}$ \\
\hline 4 & $37,50 \mathrm{a}$ & $35,50 \mathrm{a}$ & $466,50 \mathrm{ab}$ & $40,50 \mathrm{a}$ & $39,00 \mathrm{a}$ & $376,25 \mathrm{bc}$ & $12,50 \mathrm{~b}$ & $15,00 \mathrm{~b}$ & $11,25 \mathrm{~b}$ & $36,50 \mathrm{a}$ & $35,00 \mathrm{a}$ & $413,50 \mathrm{a}$ & $21,25 \mathrm{~b}$ & $20,00 \mathrm{~b}$ & $20,00 \mathrm{~b}$ \\
\hline 7 & $35,00 \mathrm{a}$ & $35,50 \mathrm{a}$ & $444,25 \mathrm{ab}$ & $41,25 \mathrm{a}$ & 39,75 a & $491,50 \mathrm{ab}$ & $8,75 \mathrm{~b}$ & $7,50 \mathrm{~b}$ & $7,50 \mathrm{~b}$ & $36,00 \mathrm{a}$ & $35,00 \mathrm{a}$ & 503,75 a & $15,00 \mathrm{~b}$ & $7,50 \mathrm{bc}$ & $10,00 \mathrm{~b}$ \\
\hline 10 & $37,75 \mathrm{a}$ & $36,75 \mathrm{a}$ & $538,75 \mathrm{a}$ & $33,00 \mathrm{a}$ & $31,50 \mathrm{ab}$ & $535,50 \mathrm{a}$ & $13,75 \mathrm{~b}$ & $6,25 \mathrm{~b}$ & $6,25 \mathrm{~b}$ & $34,25 \mathrm{a}$ & $33,00 \mathrm{a}$ & $510,50 \mathrm{a}$ & $18,75 \mathrm{~b}$ & $7,50 \mathrm{bc}$ & $5,00 \mathrm{~b}$ \\
\hline 13 & $36,50 \mathrm{a}$ & $36,50 \mathrm{a}$ & $444,50 \mathrm{ab}$ & $39,00 \mathrm{a}$ & $38,00 \mathrm{a}$ & $479,50 \mathrm{ab}$ & $0,00 \mathrm{~b}$ & $0,00 \mathrm{~b}$ & $0,00 \mathrm{~b}$ & $38,50 \mathrm{a}$ & $37,25 \mathrm{a}$ & $487,75 \mathrm{a}$ & $0,00 \mathrm{c}$ & $0,00 \mathrm{c}$ & $0,00 \mathrm{~b}$ \\
\hline
\end{tabular}

- Os valores médios seguidos pela mesma letra, em cada uma das colunas, não diferem entre si pelo teste de Tukey a 5\% de probabilidade.
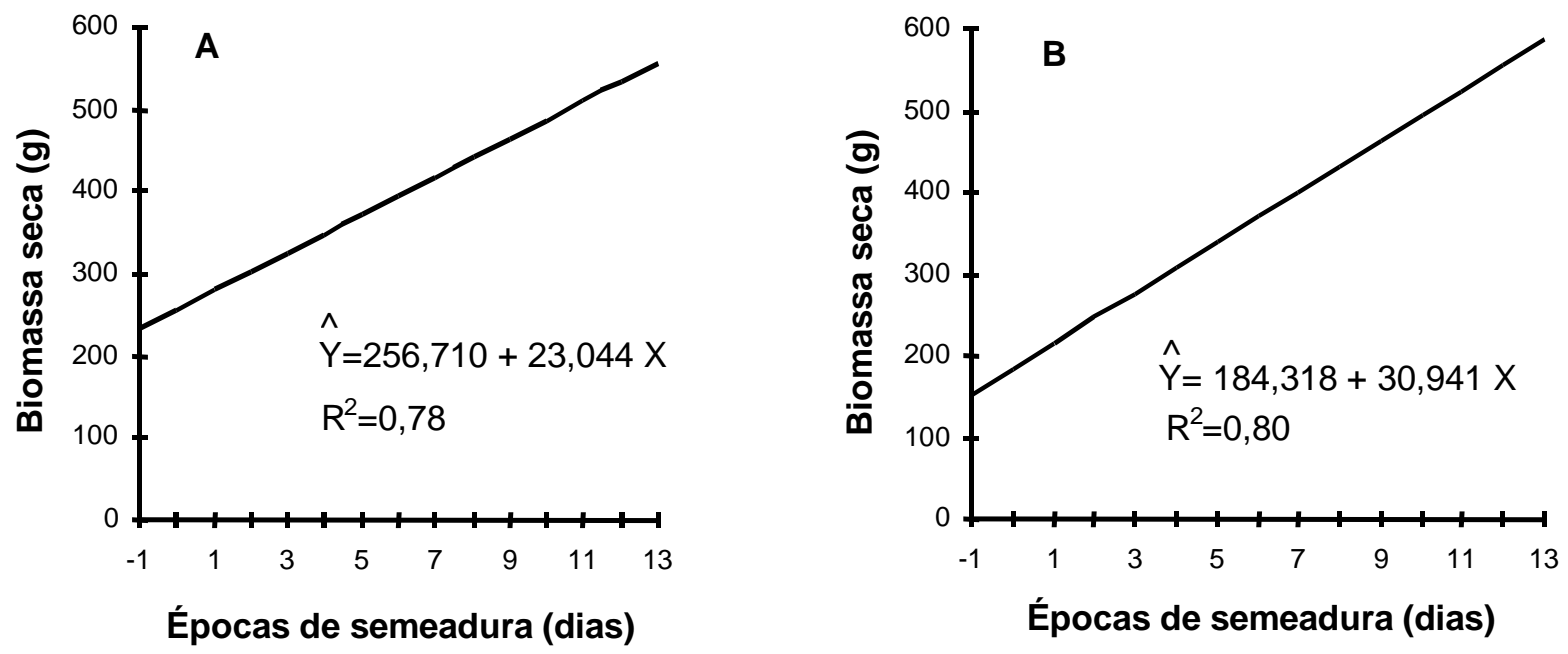

Figura 1 - Biomassa seca de plantas de girassol em função das épocas de semeadura da cultura, em relação à aplicação das doses de 536 (A) e 1.005 g e.a. ha-1 (B) do herbicida 2,4-D. Embrapa Soja, Londrina-PR, 1995/96. 
As avaliações de toxicidade nas plantas de girassol aos 28 e 42 DAS apresentaram comportamento linear em função das diversas épocas de semeadura da cultura (Figuras 3 e 4). Da mesma forma que na avaliação anterior, houve redução nos sintomas de intoxicação à medida que se afastou a semeadura da época de aplicação do herbicida. As plantas de girassol apresentaram injúrias mais severas nas três primeiras épocas de semeadura e, principalmente, na maior dose (Tabela 2). Os valores obtidos quando o girassol foi semeado aos 4 DAA não diferiram dos valores alcançados quando essa operação foi realizada aos 7 e 10 DAA, não chegando a apresentar nenhum sintoma de intoxicação pelos resíduos do produto aos 13 DAA. Os efeitos fitotóxicos da mistura glyphosate mais 2,4-D sobre o feijoeiro,
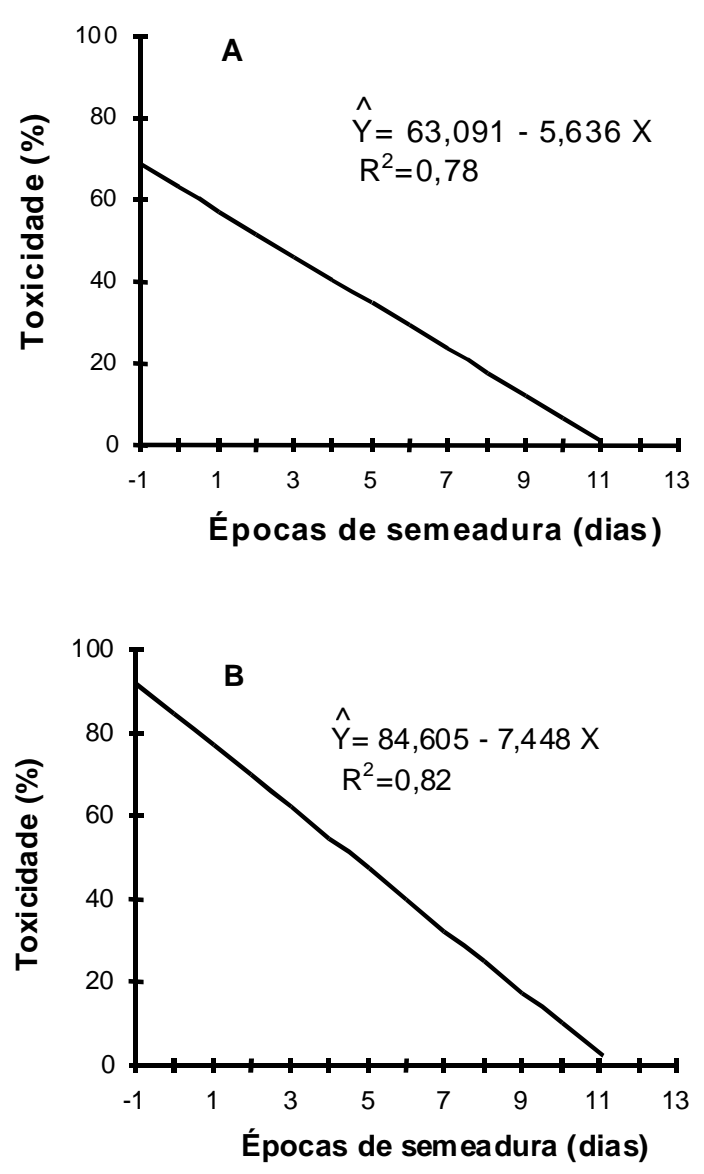

Figura 2 - Toxicidade de plantas de girassol aos 14 DAS em função das épocas de semeadura da cultura, em relação à aplicação das doses de 536 (A) e 1.005 g e.a. ha-1 (B) do herbicida 2,4-D. Embrapa Soja, Londrina-PR, 1995/96. aplicados em pré-semeadura direta da cultura, foram avaliados por Carvalho et al., (1995), os quais verificaram que as doses de $720+670 \mathrm{e}$ $720+1.005 \mathrm{~g} \mathrm{ha}^{-1}$ de glyphosate e $2,4-\mathrm{D}$, respectivamente, afetaram o desenvolvimento das plantas de feijão até cinco dias antes da semeadura. A persistência do 2,4-D em dois tipos de solo, argiloso e arenoso, foi analisada por Smith (1979). Foi verificado que a dissipação desse herbicida é mais rápida no solo arenoso, assumindo que a meia-vida do produto foi menor que sete dias. No entanto, Moyer et al. (1992) constataram que a aplicação do 2,4-D realizada durante a primavera e 15 dias antes da semeadura prejudicou o desenvolvimento da canola, ervilha, lentilha e alfafa e que houve pequena redução no peso da matéria seca total de plantas de trigo e de cevada.
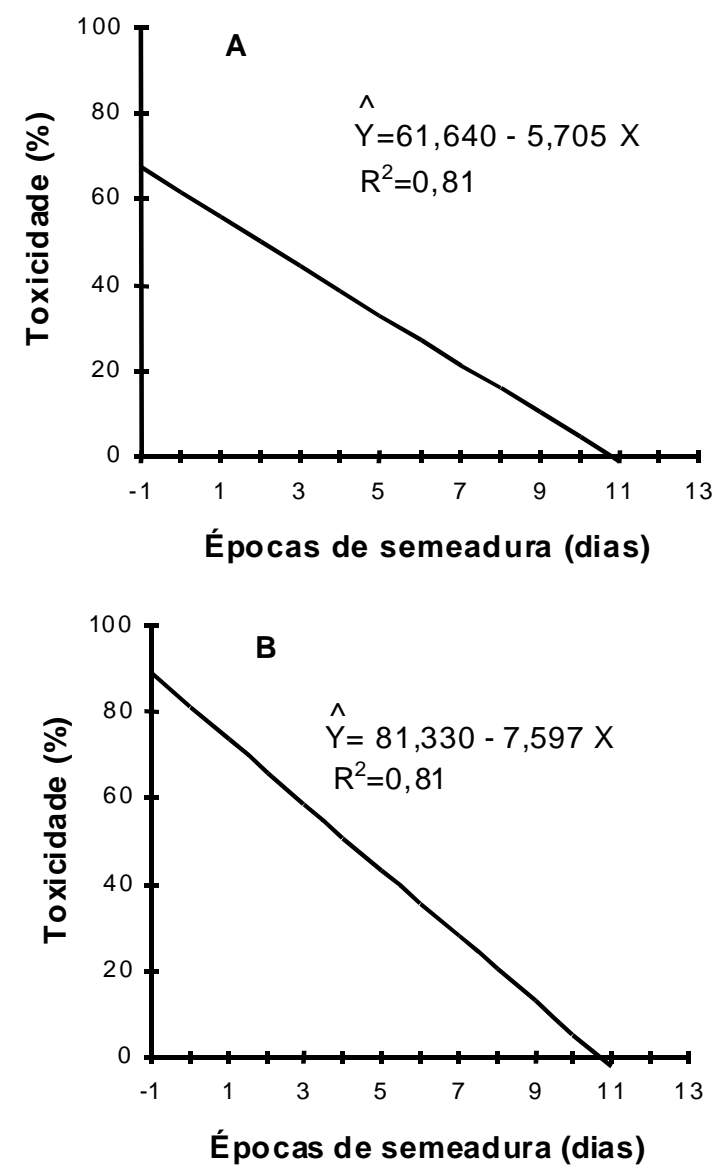

Figura 3 - Toxicidade de plantas de girassol aos 28 DAS em função das épocas de semeadura da cultura, em relação à aplicação das doses de 536 (A) e 1.005 g e.a. ha ${ }^{-1}$ (B) do herbicida 2,4-D. Embrapa Soja, Londrina-PR, 1995/96. 

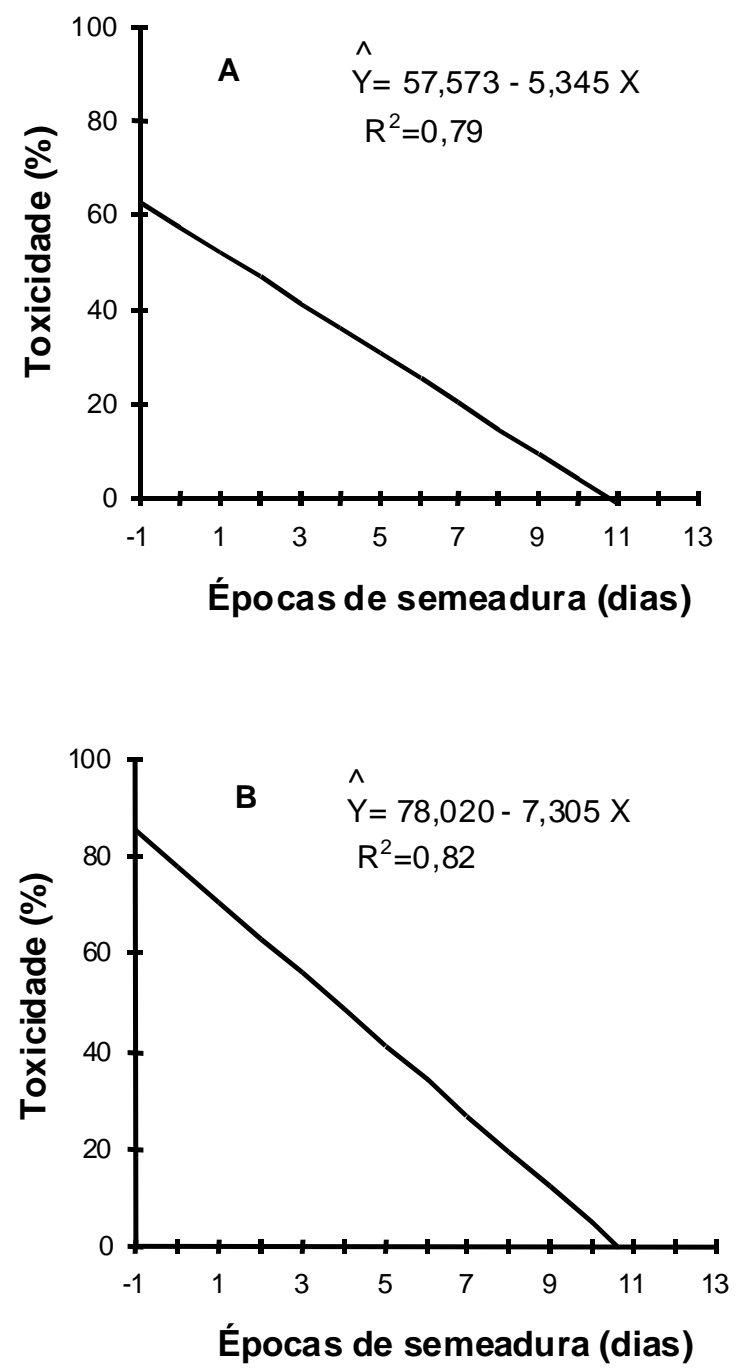

Figura 4 - Fitotoxicidade de plantas de girassol aos 42 DAS em função das épocas de semeadura da cultura, em relação à aplicação das doses de 536 (A) e $1.005 \mathrm{~g} \mathrm{e}$.a. ha-1 (B) do herbicida 2,4-D. Embrapa Soja, Londrina-PR, 1995/96.

Conclui-se, pois, deste trabalho, que, nas condições em que foram aplicados os tratamentos, o girassol sofreu injúrias mais severas nas três primeiras épocas de semeadura $(-1$, $0,1)$. Foram observados menores sintomas de toxicidade com o aumento do período entre a semeadura do girassol e a aplicação das doses do 2,4-D. Áreas tratadas com o 2,4-D nas doses de 536 e 1.005 g e.a.ha-1 podem ser cultivadas com girassol, desde que se mantenha um intervalo mínimo de quatro dias entre a aplicação do herbicida e a sua semeadura.

\section{LITERATURA CITADA}

ALTOM, J.D.; STRITZKE, J.F. Degradation of dicamba, picloram and four phenoxy herbicides in solis. Weed Sci., v.21, p.556-560, 1973.

BECKIE, H.J.; McKERCHER, R.B. Soil residual properties of DPX-A7881 under laboratory condictions. Weed Sci., v.37, p.412-418, 1989.

BREWSTER, B.D.; APPLEBY, A.P. Response of wheat (Triticum aestivum) and rotation crops to chlorsulfuron. Weed Sci., v.31, p.861-865, 1983.

CARVALHO, J.A.; SANTOS, V.L.M.; SANTOS, C.M. Efeito residual da mistura de glyphosate mais 2,4-D sobre a cultura do feijão (Phaseolus vulgaris) aplicado em pré semeadura direta. In: CONGRESSO BRASILEIRO DA CIÊNCIA DAS PLANTAS DANINHAS, 20, 1995, Florianópolis. Resumos... Florianópolis: SBCPD, 1995, p.160.

CORREAA, A.R.; GODOY, H.; BERNARDES, L.R.M. Características climáticas de Londrina. 2.ed. Londrina: IAPAR, 1982. 16p. (Circular IAPAR, 5)

EMBRAPA. EMPRESA BRASILEIRA DE PESQUISA AGROPECUÁRIA - Centro Nacional de Pesquisa de Soja (Londrina, PR). Recomendações técnicas para a cultura da soja no Paraná 1999/ 2000. Londrina: 1999. 235p. (EMBRAPA Soja-Documentos, 131).

DUAH-YENTUMI, S.; KUWATSUKA, S. Microbial degradation of benthiocarb, MCPA and 2,4-D herbicides in perfused soils amended with organic matter and chemical fertilizer. Soil Sci. Plant Nutr., v.28, p.19-26, 1982.

FOSTER, R.K.; McKERCHER, R.B. Laboratory incubation studies of chlorophenoxyacetic acids in chernozemic soils. Soil Biol. Biochem., v.5, p.333-337, 1973.

GALLANDT, E.R.; FAY, P.K., INSKEEP, W.P. Clomazone dissipation in two Montana soils. Weed Tech., v.37, p.146-150, 1989.

GRIFFIN, J.L.; BARKER, J.B. Tolerance of rice cultivars to fenoxaprop, sethoxydim and haloxyfop. Weed Sci., v.38, p.528-531, 1990.

LOOS, M.A. Phenoxyalkanoic acids. In: KEARNEY, P.C., KAUFMAN, D.D., Herbicides. New York: Marcel Dekker, 1975. p.1-28.

MOYER, J.R.; BERGEN, P.; SCHAALJE, B. Effect of 2,4-D and Dicamba residues on following crops in conservation tillage systems. Weed Tech., v.6, p.149-155, 1992. 
PLUMB, T.R.; NORRIS, L.A.; MONTGOMERY, M.L. Persistence of 2,4-D and 2,4,5 $\mathrm{T}$ in chaparral soil vegetation. Bull. Environ. Contam. Toxicol., v.17, p.1-8, 1977.

RODRIGUES, B.N.; ALMEIDA, F.S. Guia de herbicidas. 3.ed. Londrina, PR, 675p. 1995.

SILVA, J.F.; SILVA, J.F. Curso de especialização por tutoria a distância. Curso de proteção de plantas. Classificação dos herbicidas (mod.5.2). Brasília: ABEAS, 1991. p.38-89.

SOUZA, A.P.; LOURES, E.G.; SILVA, J.F.; RUIZ, H.A Efeito do oxyfluorfen, 2,4-D e glyphosate na atividade microbiana de solos com diferentes texturas e conteúdos de matéria orgânica. Planta Daninha, v.14, p.55-64, 1996.
SMITH, A.E. Relative persistence of di-and trichlorophenoxyalkanoic acid herbicides in Saskatchewan soils. Weed Res., v.18, p. 275279, 1978.

SMITH, A.E. Soil persistence experiments with $\left({ }^{14} \mathrm{C}\right)$ 2,4-D in herbicidal mixtures and field persistence studies with tri-allate and trifluralin both singly and combined. Weed Res., v.19, p. 165-170, 1979.

TORSTENSSON, N.T.L.; STARK, J.; GÖRANSSON, B. The effect of repeated applications of 2,4-D and MCPA on their breakdown in soil. Weed Res., v.15, p.159-164, 1975. 